\title{
IoT based Smart Motor Cycle Helmet
}

\author{
Bhavesh Shahare, Shivani Chawde, Rakesh Gudafwar, Harshada Pal, \\ Purvi Bobade, Shyam Bawankar* \\ Department of Electronics and Telecommunication, JD College of Engineering and Management, \\ Nagpur, India \\ Email:*shyam_bawankar@rediffmail.com
}

\begin{abstract}
The main purpose of this paper is to urge the two wheeler motor cycle riders to wear a helmet. In India, most of the death cases occur due to the two wheeler accidents. In most of the cases, rider suffers head injuries, which leads to death. In order to reduce the number of accidents, this research work proposes a smart helmet, which will be very useful for the twowheeler riders. In general, two-wheeler accidents occur due to the high consumption of alcohol by the rider. The proposed smart helmet ensures the safety of the rider, while driving on the road. The proposed model comprises of an alcohol detection, accident identification, location tracking, hands-free device, solar powered module and fall detection. The proposed smart helmet will be connected to the ignition. Henceforth, if the rider does not wear a helmet, the ignition will not be triggered to start the two-wheeler. For handling an emergency situation, GSM module is used to send an alert message to the registered mobile number.
\end{abstract}

Keywords- Arduino Uno, alcohol detection sensor, RF module, GSM module, GPS module, ultrasonic sensor, IR sensors, camera, relay, accelerometer

\section{INTRODUCTION}

Now-a-days most of the people are utilizing two-wheeler vehicle to move from one place to another place. Despite the hype, all the riders are not aware on wearing a helmet. Some people are used to drive the bike in a high speed by not wearing a helmet, due to which most of the accidents occur and most of the people die by suffering serious head injuries. Most of the accidents occur due to drunken-drive and helmetless driving conditions. Thus, the main objective of this research work is to strongly insist the rider to wear a helmet while riding, and if the rider does not wear a helmet, then the bike will not start. This technology can be implemented with the help of alcohol detection, accident identification, location tracking, 
hands-free device, solar power, and fall detection modules. Initially, the helmet will be connected to the ignition and if the rider is not wearing a helmet, the ignition will not turn ON. A camera will be used to record the rider while driving on the road. Thus, with the help of a smart helmet, the number of death cases due to accidents can be reduced and save the lives of young people.

\section{PROPOSED SYSTEM}

The purpose of the proposed system is to address two main issues, which motivates for developing this project.

1) To identify whether the rider is wearing a helmet.

2) To detect alcohol consumption in the rider.

The proposed research work has designed a system in such a way that the helmet identifies both the aforementioned conditions before the ignition is turned $\mathrm{ON}$ and the ignition will be started only if both the conditions are satisfied. To perform this, the proposed system mainly includes an alcohol sensor and helmet sensing switch. The first condition to start the ignition is by checking whether the rider is wearing a helmet or not, if not the first condition will not be satisfied. If the rider wears a helmet, then the condition will be satisfied. Alcohol sensor MQ3 is used for the detection of alcohol concentration to find out whether the driver is drunken or not. According to the alcohol concentration level, the output will be provided by the sensor. The second condition is to detect the consumption of alcohol, for that an alcohol sensor (MQ3) is used to detect the level of alcohol consumption in the rider, then the second condition will be satisfied. The engine will be ready to start, if both the conditions are satisfied. Switch is used to detect whether the biker has worn a helmet or not. It is connected to an external battery to meet the power requirements. The bike gets started only when the helmet sensing switch is ON, otherwise the bike will not be started. IR sensor is used to detect the helmet. Once the rider wears a helmet, the IR sensor will give a signal to the controller. Accelerometer (ADXL335) is used to detect the accident. The ultrasonic sensor is used to detect the distance of next vehicle in the front and when the vehicle is very nearer to another 
Journal of Electronics and Informatics (2021)

Vol.03/ No.01

Pages: $15-22$

https://www.irojournals.com/iroei/

DOI: https://doi.org/10.36548/jei.2021.1.002

vehicle, then the ultrasonic will become active by connecting to the buzzer, as a result the buzzer will turn ON and the rider will get an alert. GPS module is used to locate the geographical position of the rider. Whenever, the accident occurs, GPS module sends an alert message to the registered mobile number. Camera has been used to record the rider while driving and it will be externally connected to the helmet. Here, nigh vision lens are externally utilized to visualize the driver clearly even in the night times so that the chance of accident will be highly reduced and it also helps to visualize the next vehicle or any other obstacle to the rider. A Controller is device used here to control all the functions of different blocks implemented in the system.

\section{BLOCK DIAGRAM}

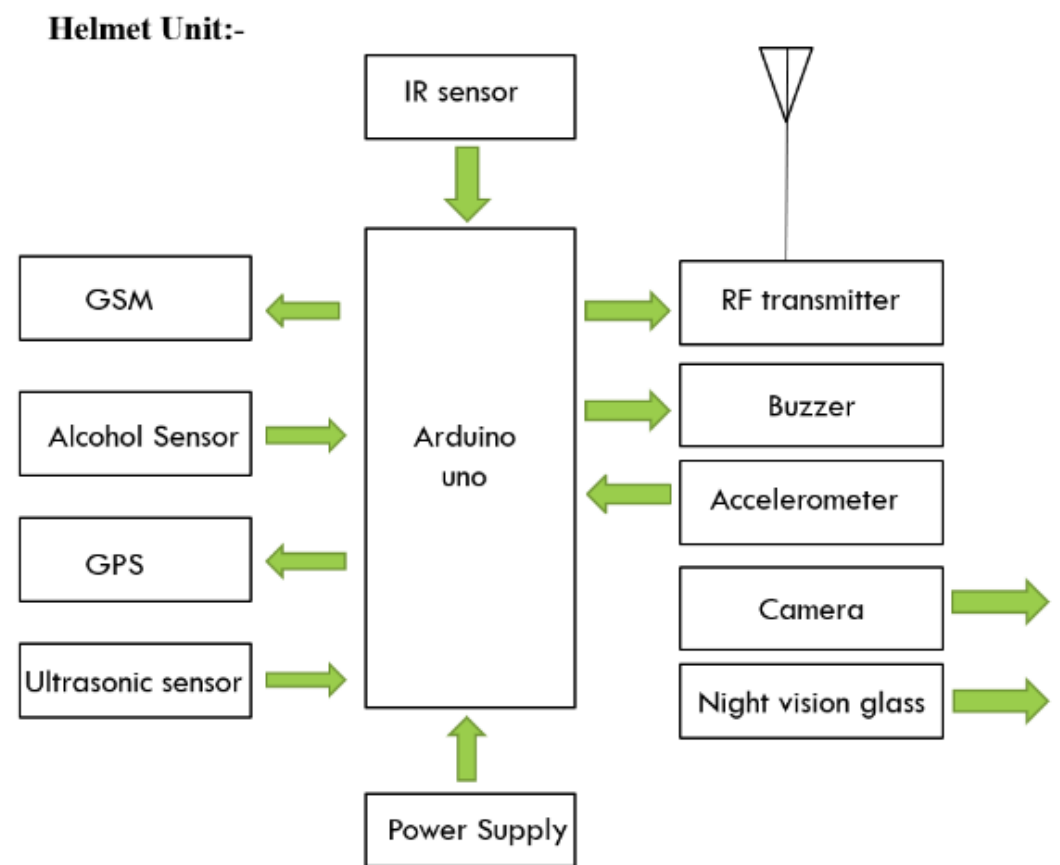

Figure 1

ISSN: 2582-3825 (online) 
Vehicle Unit :-

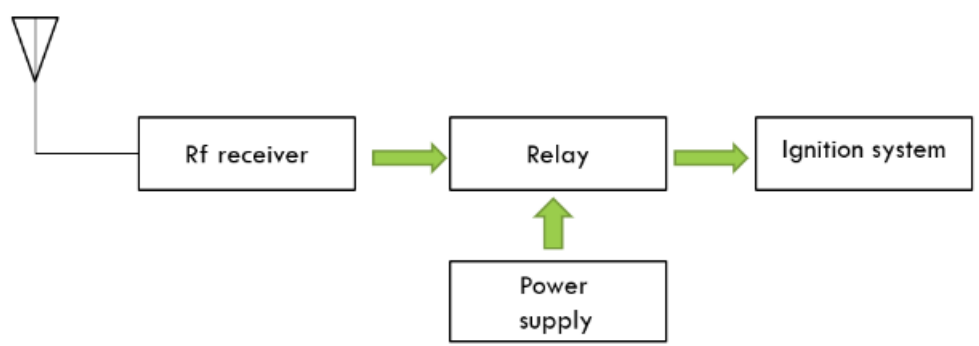

Figure 2

\section{HARDWARE AND SOFTWARE REQUIREMENTS}

\section{Hardware Requirement:}

Alcohol Sensor: Alcohol sensor is used to detect alcohol gas in air and an analog voltage will be obtained in the output reading. The sensor is activated for temperature in the range of -10 to $50^{\circ} \mathrm{C}$, by having a power supply less than $150 \mathrm{MA}$ to $5 \mathrm{~V}$. The sensing range will be $0.04 \mathrm{mg} / \mathrm{L}$ to $4 \mathrm{mg} / \mathrm{L}$.

Arduino UNO: Arduino UNO is used as a microcontroller. It has 14 digital I/O pins. Out of 14 pins, 6 pins can be used as PWM output. Further, 6 analog inputs, and a $16 \mathrm{MHz}$ ceramic resonator are utilized. It also consists of a USB connection, power jack and reset button.

RF module: RF module is used to send and receive the data with a frequency range of $434 \mathrm{mHz}$. Transmission occurs in the range of $1 \mathrm{kbps}$ to $10 \mathrm{kbps}$.

Buzzer: It is used as an audio signal.

Ultrasonic sensor: Ultrasonic sensor is used to measure a distance by emitting the ultrasonic sound waves and converts the reflected sound into an electrical signal with an ultrasound frequency of about $120 \mathrm{kHz}$. 
GPS module: GPS module it a satellite based navigation system that is used to provide the location and time related information to the user. Antenna gain is $50 \mathrm{~dB}$. Interfaces that can be utilized here is UART, USB, SPI and DDC. Tracking and navigation is $160 \mathrm{dBm}$.

IR sensor: IR sensor consists of IR transmitter and receiver, op-amp, variable resistor and output LED. It can sense up to a range of $20 \mathrm{~cm}$. Wavelength is in the range of $700 \mathrm{~nm}-$ $1 \mathrm{~mm}$. The operating voltage and supply current will be 5VDC and $20 \mathrm{~mA}$ respectively.

GSM module: GSM module is used for establishing a communication between a mobile device and two-wheeler. It has a dual band of 900/1800MHz. Supply voltage will be 5V and low power consumption is at $1.5 \mathrm{~mA}$.

Relay: Relay is an electrical switch operated by the electromagnet. It is used to time the delay open and close of contact. It is used to control the high voltage circuit with the help of a low voltage signal.

Accelerometer: Accelerometer is an electromechanical device used to measure acceleration force due to gravity. It has 3-axis acceleration measurement. Output signal are analog voltage, i.e. proportional to acceleration.

Camera: It will not record video while driving.

Night vision glass: It help to ascertain the clear darkly by magnifying the encompassing light and therefore the object clearly.

Software requirement: Ardiuno IDE Version-1.8.13 


\section{RELATED TO WORK}

\section{A. TRANSMITTER SECTION}

\section{Helmet unit:}

It describes the planning of an efficient safety system for motorcycle, so as to avoid accidents that occur mainly due to the alcohol consumption. The proposed research work has combined both the system helmet and alcohol sensor with a single embedded system. Transmitter section is directly connected to the alcohol sensor, helmet sensing switch, controller, encoder and RF transmitter. The alcohol sensor will be attached inside the helmet .The controller reads data from the sensor and detects whether the rider has non-alcoholic breath as the helmet sensor has switched close in positioning the digital output to an encoder only if the first two conditions are satisfied. It encodes one of the active inputs to a coded binary output. RF transmitter transmits this coded binary output from the encoder. In this RF system, the digital form of data is shown in the form of amplitude of carrier.

\section{B. RECEIVER SECTION}

\section{Vehicle unit:}

The receiver is placed on the bike. It mainly consists of an RF receiver, RF decoder, controller, audio and sound indicator (buzzer). This section will gain this facility from the bike battery. RF transmitter transmits the coded binary data and RF receiver receives the transmitted data and sends it to RF decoder to decode the input and transfers four bit digital data to the controller until the address bit of encoder and decoder gets matched. Vehicle engine is operated by the controller when it receives digital data from the transmitter section. The visual indication is provided by the controller unit according to the coding. It operates the engine / DC motor, when the conditions are satisfied and therefore the buzzer will give sound indication when the rider's pulse goes abnormal. All these output operations are performed by a relay circuit but the relay cannot be operated directly, so there is an additional use of a relay interface. The provided system is used by the automobile department to avert the abnormal circumstances 
Journal of Electronics and Informatics (2021)

Vol.03/ No.01

Pages: $15-22$

https://www.irojournals.com/iroei/

DOI: https://doi.org/10.36548/jei.2021.1.002

\section{CONCLUSION}

Accident cases occur due to motorcycles. The major accidents are increased by drinking alcohol and this is due to the absence of a helmet. In this we have developed an electronic intelligent helmet system, which efficiently check wearing of helmet and drunk -driving. By implementing this technology, the rate of accident due to alcohol consumption can be significantly reduced. The proposed research work has introduced advanced sensor technologies and radio frequency during this project to enhance its efficiency.

\section{REFERENCES}

[1] Keesari Shravya(1), Yamini Mandapati(2), Donuru Keerthi(3), Kothapu Harika(4), and Ranjan K. Senapati(5) VignanaJyothi Institute of Engineering and Technology, Bachupally, Hyderabad, Telangana, India

[2] Intelligent HelmetVishnu. M. B.1 Binoy. T. S.2 Harikrishnan. M. R.3 Shahin. M. Abdulla41,2,3UG Student 4Assistant Professor1,2,3,4Department of Electronics\&CommunicationEngineering1,2,3,4Matha college of Technology 2017

[3]A. Srikrishnan, K. Senthil Kumar and S. Ravi, Cloud Incorporated Smart Helmet Integrated with Two-Wheeler Communication Setup, International Journal on Computer Technology and Applications volume (9): Issue (4) on 2016.

[4]Mangesh Jadhawar, Gauri Kandepalli, Ashlesha Kohade, Rajkumar Komati, smart helmet safety system using atmega 32, International Journal of Research in Engineering and Technology Volume: 05 Issue: 05 on May-2016.

[5]Akshay Kumar Yalkar, Harsha Vardhan Singh N, Jagadevan V, Nandini C, K.Ezhilarasan \& Pushpa Mala.S, Development Of A Smart Interface For Safety And Protection Of Automotives , International Journal of Image Processing (IJIP), Volume Issue (4) : 2015.

[6]Manasi Penta, Monali Jadhav and Priyanka Girme, published in International Journal of Research in Engineering and Technology Volume: 04 Issue: 02 on April 2015.

[7]Abhinav Anand, Kumar Harsh, Kushal Kumar, Sourav Gouthi, Microcontroller Based Smart Wear for Driver Safety, International Journal of Research in Engineering and Technology Volume: 04 Issue: 05 on May-2015. 
Journal of Electronics and Informatics (2021)

Vol.03/ No.01

Pages: $15-22$

https://www.irojournals.com/iroei/

DOI: https://doi.org/10.36548/jei.2021.1.002

[8]Subia Sayeed, Drunken Drive Protection System, International Journal of Innovations in Engineering Research and Technology ISSN: 2394-3696 VOLUME 2, ISSUE 6, JUNE-2015. [9]Muthiah M, Aswin Natesh V, Sathiendran R K, Smart Helmets for Automatic Control of Headlamps, International Conference on Smart Sensors and Systems on 2015. 